\title{
O PRINCÍPIO DA SUPREMACIA DO INTERESSE PÚBLICO NA CONTEMPORANEIDADE SOB A ÓTICA DOS DIREITOS FUNDAMENTAIS
}

\author{
THE PRINCIPLE OF THE SUPREMACY OF THE PUBLIC INTEREST IN \\ CONTEMPORARY TIMES FROM THE POINT OF VIEW OF FUNDAMENTAL \\ RIGHTS
}

Lucas Gonçalves da Silva ${ }^{1}$

Antonio Evangelista de Souza Netto ${ }^{2}$

Camila Cardoso Takano ${ }^{3}$

\section{RESUMO}

O presente artigo tem como objetivo analisar, numa perspectiva histórica, o princípio da supremacia do interesse público sobre o interesse particular e sua (in)aplicação na contemporaneidade. Sabe-se que os direitos fundamentais representam o elemento-base sobre o qual se desenvolveu o sistema constitucional do atual Estado democrático brasileiro. Diante das mudanças ocorridas na sociedade hodierna, pretende-se demonstrar as atuais relações estabelecidas entre o princípio da supremacia do interesse público e os direitos fundamentais. Utilizar-se-á uma pesquisa teórica a partir de um arsenal bibliográfico completo capaz de instigar o leitor a refletir acerca da plausibilidade da (in)aplicação do aludido princípio.

\footnotetext{
${ }^{1}$ Pós-doutor pela UFBA e pela Università Degli Studi G. d'Annunzio. Doutor e Mestre pela PUC/SP. Professor da Graduação e do Programa de Mestrado da UFS. Vice-Presidente do CONPEDI. E-mail: lucasgs@uol.com.br.

${ }^{2}$ Juiz de Direito de Entrância Final do Tribunal de Justiça do Estado do Paraná. Pós-doutorando em Direito pela Universidade de Salamanca - Espanha. Pós-doutorando em Direito pela Universitá degli Studi di Messina - Itália. Pós-doutorando em Direito pela Universidade de Coimbra - Portugal. Doutor em Filosofia do Direito pela Pontifícia Universidade Católica de São Paulo - PUC/SP (2014). Mestre em Direito Empresarial pela Pontifícia Universidade Católica de São Paulo - PUC/SP (2008). Vice-Presidente da Comissão de Empresas Familiares e Holding do Instituto Brasileiro de Direito de Família-IBDFAM Coordenador do Núcleo de EAD da Escola da Magistratura do Tribunal de Justiça do Estado do Paraná - EMAP. Professor da Escola Nacional de Formação e Aperfeiçoamento de Magistrados - ENFAM. Professor da Escola da Magistratura do Tribunal de Justiça do Estado do Espírito Santo - EMES. Professor da Escola da Magistratura do Tribunal de Justiça do Estado do Paraná EMAP. Professor em cursos de pós-graduação. Parecerista da revista do curso de mestrado e doutorado em direito da Faculdade Autônoma de Direito de São Paulo - FADISP. Diretor Científico da Coleção Processo e Constituição da Editora Prismas. Participates in Judicial Exchange at Harvard University - Law School. Membro do Fonajuc Fórum Nacional de Juízes Criminais. Membro da Academia de Cultura de Curitiba/PR. Membro da Soberana Ordem do Mérito de Saint Yves de Tréguier - França. Comendador da Ordem do Mérito Cívico e Cultural - SBHM. ${ }^{3}$ Mestranda em Direito Constitucional pela UFS. Especialista em Direito do Trabalho pela Universidade Candido Mendes. Graduada em Direito pela UFOP. Servidora Pública do TRT $20^{\mathrm{a}}$ Região. E-mail: camilatakano@yahoo.com.br.
} 
PALAVRAS-CHAVE: Princípio. Supremacia do interesse público. Direitos fundamentais. Estado Democrático de Direito. Constituição de 1988.

\begin{abstract}
This article aims to analyze, from a historical perspective, the principle of the supremacy of public interest over private interest and its (in)application in contemporaneity. It is known that fundamental rights represent the basic element on which the constitutional system of the current democratic Brazilian State was developed. Given the changes that have taken place in today's society, it is intended to demonstrate the current relationships established between the principle of the supremacy of the public interest and everyday life. A theoretical research will be used from a complete bibliographic arsenal capable of instigating the reader to reflect on the plausibility of the (in)application of the aforementioned principle.
\end{abstract}

KEYWORDS: Principle. Supremacy of public interest. Fundamental rights. Democratic rule of law. Constitution of 1988.

\title{
INTRODUÇÃO
}

As sociedades transformam-se no decurso do tempo e, como consequência, ocorrem diversas mudanças de cunho social, político e econômico. Nesse aspecto, o direito e as normas constitucionais necessitam adequar-se ao novo cenário concebido no intuito de formar um arcabouço legislativo a fim de contemplar ao máximo as situações jurídicas emergentes. Um dos pontos principais do presente artigo é demonstrar a importância da compreensão acerca dos direitos fundamentais e a necessidade de concretização dos mesmos para a consolidação legítima do Estado Democrático de Direito.

Sabe-se que a reformulação do pensamento crítico ocorre através da evolução social. Para que haja um efetivo bem-estar coletivo tal transformação deve ocorrer de maneira cautelosa, tendo como base principiológica os direitos fundamentais. Nesse viés, o presente artigo busca analisar a (in)aplicação do princípio da supremacia do interesse público sobre o interesse particular no contexto hodierno. 
No âmbito do Direito Administrativo, a atuação do poder público tem-se pautado, por vezes, na falta de transparência e em condutas arbitrárias ${ }^{4}$ quando se trata da concretização de interesses públicos e de interesses particulares em conflito. Tal conduta ameaça a materialização dos direitos fundamentais contidos na Constituição de 1988 e, consequentemente, configura uma afronta aos ditames constitucionais.

Os novos valores e concepções precisam ser incorporados no escopo social e, ao mesmo tempo, devem garantir um desenvolvimento positivo e útil para indivíduos, instituições e poder público. Para tanto, a ausência de restrições e privações à dignidade da pessoa humana é indispensável para a consolidação de uma base justa e sólida do sistema constitucional de um Estado Democrático de Direito. Assim, torna-se necessária a configuração de um equilíbrio na resolução dos conflitos existentes entre os interesses da Administração Pública e os interesses dos particulares.

A partir de uma pesquisa teórica (MONTEIRO; MEZZAROBA, 2014), baseada em um arsenal bibliográfico completo, ir-se-á clarificar o problema apresentado referente à aplicabilidade ou inaplicabilidade do princípio da supremacia do interesse público. Haverá reflexões e sugestões para uma possível solução aos casos concretos conflituosos apresentados, empregando, assim, a pesquisa prática de maneira subsidiária (MONTEIRO; MEZZAROBA, 2014).

Isto posto, partindo-se da premissa de que os direitos fundamentais são os responsáveis pela promoção da paz e da justiça social, os novos conceitos e valores introduzidos na sociedade devem observá-los. Nesse parâmetro, verificar-se-ão quais os caminhos a serem percorridos a fim de coadunar com os ditames democráticos com o objetivo de afastar o perigo da existência de um patamar hierárquico privilegiado em torno do princípio da supremacia do interesse público sobre o interesse privado. Buscar-se-á, sobretudo, a notoriedade de conceitos éticos e morais para o alcance do bem estar de toda coletividade.

\section{OS DIREITOS FUNDAMENTAIS COMO A BASE DA CONSTITUIÇÃO DE 1988}

José Afonso da Silva, ilustre jurista brasileiro, classifica as normas jurídicas em três grupos conforme o grau de variação da eficácia das mesmas. O primeiro grupo diz respeito às

\footnotetext{
${ }^{4}$ Em alguns casos práticos, a atuação da Administração Pública demonstra-se autoritária, o que remete ao pensamento outrora consolidação na época em que surgiu o Direito Administrativo, como será verificado no decorrer do presente estudo.
} 
normas de eficácia plena, com aplicabilidade direta, imediata e integral, inexistindo dependência quanto à atuação do legislador. No segundo grupo localizam-se as normas de eficácia contida, cuja aplicabilidade é direta, imediata e não-integral, enunciando uma reserva legal para existência de possíveis restrições. Por fim, o terceiro e último grupo compõe-se por normas de eficácia limitada, com aplicabilidade indireta, mediata e reduzida, não recebendo do legislador a normatividade suficiente e, por isso, não há efeito imediato. O mencionado grupo ainda se subdivide em outros dois ramos, composto pelas normas de princípio programático e pelas normas de princípio institutivo ou organizacional (SILVA, 2012a, p. 81).

Deste modo, percebe-se que a variação das normas quanto à eficácia pode ter menor ou maior grau de oscilação. Com isso, a Constituição de 1988 estabeleceu em seu artigo $5^{\circ}, \S^{\circ}$, $\mathrm{CRFB} / 88$, que as normas definidoras de direitos e garantias fundamentais possuem aplicação imediata, o que significa afirmar, de antemão, que as mesmas apresentam eficácia plena (BRASIL, 1988). Assim, tais normas não precisariam de qualquer intervenção do legislador para terem seus objetos elencados concretizados. Entretanto, as referidas normas fundamentais possuem mandamentos distintos de acordo com o papel que exercem na Magna Carta e, uma vez que não possuem a mesma eficácia em todas as versões, há inúmeras discussões sobre a temática.

Nesse sentido, Silva leciona que as normas de aplicação imediata são embasadas por todos os elementos necessários para sua incidência, sendo desnecessárias quaisquer intervenções para sua concretude (SILVA, 2012b, p. 180). Assim, o autor afirma que o sentido normativo do texto constitucional em seu artigo $5^{\circ}, \S 1^{\circ}, \mathrm{CRFB} / 88$, consagraria a aplicação imediata das normas de direitos fundamentais (SILVA, 2012b, p. 180-181). ${ }^{5}$

\footnotetext{
${ }^{5}$ José Afonso da Silva faz uma análise sobre o artigo $5^{\circ}, \S^{\circ}$ da $\mathrm{CF} / 88$ e descreve as normas de aplicação imediata como: "São dessa natureza as normas constitucionais dotadas de todos os meios e elementos necessários à sua pronta incidência aos fatos, situações, condutas ou comportamentos que elas regulam. A regra é que as normas definidoras de direitos e garantias individuais sejam de aplicabilidade imediata. Mas aquelas definidoras de direitos sociais, culturais e econômicos nem sempre o são, porque não raro dependem de providências ulteriores que lhe completem a eficácia e possibilitem sua aplicação". E, ainda, tece sobre o sentido normativo do texto: "Então, diante do que se acaba de dizer, que valor tem o texto do parágrafo sob análise? Pelo seu enunciado bem se vê que abrange as normas que revelam os direitos individuais do art. $5^{\circ}$ e os sociais, nos termos dos arts. $6^{\circ}$ a 11. Isso, contudo, não resolve todas as questões, porque a Constituição mesma faz depender de legislação ulterior a aplicabilidade de algumas normas definidoras de direitos sociais e coletivos. Por regra, as normas que consubstanciam os direitos fundamentais democráticos e individuais são de aplicabilidade imediata, enquanto as que definem os direitos sociais tendem a sê-lo também na Constituição vigente, mas algumas, especialmente as que mencionam uma lei integradora, são de eficácia limitada e aplicabilidade indireta. Então, em face dessas normas, que valor tem o disposto no $\S 1^{\circ}$ do art. $5^{\circ}$, que declara todas de aplicação imediata? Em primeiro lugar, significa que elas são aplicáveis até onde possam, até onde as instituições ofereçam condições para seu atendimento. Em segundo lugar, significa que o Poder Judiciário, sendo invocado a propósito de uma situação concreta nelas garantida, não pode deixar de aplicá-las, conferindo ao interessado o direito reclamado, segundo as instituições existentes". O autor ressalta, ainda, que o Poder Judiciário deve, obrigatoriamente, satisfazer toda manifestação no sentido de aplicar as normas fundamentais toda vez em que for demandado (SILVA, 2012b, p. 180-181).
} 
Preliminarmente, entende-se por núcleo essencial os componentes que formam a própria substância da Constituição, e não aqueles meramente acidentais (SARLET, 2007a, p. 438). ${ }^{6}$ Os direitos fundamentais enquadram-se, portanto, no centro do sistema constitucional brasileiro, uma vez que foram eleitos pelo legislador como a principal diretriz para o alcance de uma vida condigna e justa.

Nesse contexto, os direitos fundamentais, em razão de sua multifuncionalidade, subdividem-se em direitos de defesa e direitos a prestações. No primeiro caso incluem-se os direitos de liberdade, de igualdade e as garantias no âmbito dos direitos sociais, permanecendo no contexto da abstenção estatal. Asseguram, portanto, a esfera de liberdade individual contra as ingerências ilegítimas do Estado, provenientes do Poder Executivo, Legislativo ou Judiciário. São direitos subjetivos que independem de concretização do legislador, possuindo suficiente normatividade.

Mendes afirma que os direitos fundamentais, enquanto direitos de defesa, "intentam proteger contra ingerências dos poderes públicos contra também abusos de entidades particulares, de forma que se cuida de garantir a livre manifestação da personalidade, assegurando uma esfera de autodeterminação do indivíduo" (2007, p. 3-4).

A dignidade humana, por sua vez, caracteriza-se como um princípio jurídico de status constitucional referente a um valor fundamental, sendo parte do conteúdo dos direitos fundamentais (BARROSO, 2019). Tal instituto assume importante função demarcatória, uma vez que é a partir do seu núcleo que irradiam todos os outros direitos materialmente fundamentais previstos na Constituição de 1988. Por isso, o aludido princípio deve receber a máxima proteção, independente da posição formal em que se encontra, da dimensão de direitos a qual pertence e do tipo de prestação que ele assegura (BARROSO, 2019).

Nessa seara, o princípio da dignidade humana é aplicado com o objetivo de conceder unidade e objetividade a todo sistema constitucional, afastando qualquer conceituação ampla e vaga que dê margens para afronta aos direitos fundamentais. O seu conteúdo mínimo a ser protegido deve englobar questões como a laicidade, a neutralidade política e a universalidade, a fim de garantir uma noção de dignidade aberta, plural e plástica, como afirma Barroso (2019). ${ }^{7}$

\footnotetext{
${ }^{6}$ Existem três teorias acerca do conteúdo essencial dos direitos fundamentais: teoria relativa, absoluta e mista. Na primeira teoria há uma relativização do conteúdo essencial, que será determinado pelo princípio da proporcionalidade, onde haverá a proibição de excesso (para os direitos de defesa) ou a proibição de proteção deficiente (no caso de direitos de prestação). No que se refere à segunda teoria, a própria denominação (absoluta) leva a crer sobre a existência de um núcleo fixo, independente de ponderação. Por último, destaca-se a teoria mista, que defende a permanência de um núcleo absoluto dos direitos fundamentais, cercado por direitos passíveis de intervenções estatais (PESSOA, 2009, p. 23-24).

${ }^{7}$ Barroso afirma, ainda, que qualquer conceituação vinculada à religião ou ideologia deve ser afastada, uma vez que isso proporcionaria riscos à aplicação justa e legal do princípio da dignidade da pessoa humana.
} 
A dignidade da pessoa humana estaria, por conseguinte, inserida no embasamento teórico-normativo para fundamentar todas as dimensões dos direitos fundamentais, ${ }^{8}$ principalmente devido a sua magnitude universal, concedendo valor e concordância prática ao sistema de direitos fundamentais. Como consequência, tem-se o enquadramento da pessoa humana como fundamento e finalidade de todo Estado Democrático de Direito (SARLET, 2007b, p. 79-80).

Sarlet assevera que ao se tratar de relações intersubjetivas numa dimensão jurídiconormativa, não se pode aceitar uma afirmação genérica em torno dos direitos fundamentais e da dignidade da pessoa. Tal conduta seria vazia e abstrata demais, levando ao cometimento de abusos e interpretações equivocadas (2007b, p. 147).

Sob tal ótica, vislumbra-se que a atuação do Estado é fundamental para a proteção dos direitos fundamentais contidos no texto constitucional. $\mathrm{O}$ poder estatal vincula-se à noção de governo e de direito público, devendo buscar a sistematização das demandas entre a Administração Pública e seus indivíduos, garantindo o bem-estar de toda sociedade. Todavia, ao conceder primazia à necessidade estatal em detrimento da tutela de alguns direitos fundamentais, individuais e coletivos, o poder público atua de maneira arbitrária.

Dessa forma, analisar-se-á a origem do princípio da supremacia do interesse público para capacitar o leitor a compreender os seus reflexos nos dias de hoje. Pretende-se, no decorrer do presente estudo, encontrar a metodologia adequada para garantir o equilíbrio entre as demandas públicas e privadas em respeito aos direitos fundamentais contidos na Magna Carta de 1988.

\section{PRINCÍPIO DA SUPREMACIA DO INTERESSE PÚBLICO: DA ORIGEM AOS TEMPOS MODERNOS}

O direito administrativo que surgiu durante a Revolução Francesa em 1800 foi marcado por um conteúdo processual taxativamente favorável à Administração Pública. Utilizou-se como parâmetro principal o dogma absolutista para defesa da posição de verticalidade do poder público e relação aos seus "administrados", 9 na qual aquele era protegido pelo princípio da supremacia do interesse público sobre o interesse particular (BINENBOJM, 2005, p. 118-125).

\footnotetext{
${ }^{8}$ Refere-se, aqui, aos direitos de primeira, segunda e terceira dimensões, tradicionalmente estudados pela doutrina, bem como às novas dimensões emergentes na modernidade, tendo em vista que todas elas utilizam os direitos fundamentais e a dignidade da pessoa humana como embasamento teórico-normativo.

${ }^{9}$ Nas sociedades contemporâneas, o termo "administrado" caiu em desuso, uma vez que sua utilização estaria vinculada a um regime autoritário onde o poder público ficava em uma posição hierarquicamente superior aos
} 
Já naquela época, vislumbrava-se a crise dos paradigmas do direito administrativo devido a três fatores principais, quais sejam, o próprio princípio da supremacia do interesse público sobre os interesses privados, a legalidade administrativa como vinculação positiva à lei e a intangibilidade do mérito administrativo. O princípio da supremacia do interesse público passou a ser questionado por servir de fundamentação e legitimação para todo o sistema administrativo composto de privilégios. Além disso, a legalidade administrativa como vinculação positiva à lei seria uma suposta submissão total do agir administrativo à vontade legislativa. A intangibilidade do mérito administrativo demonstrou, por sua vez, que a discricionariedade da administração seria incontrolável pela própria administração, pelo Poder Judiciário e pelos cidadãos (BINENBOJM, 2005, p. 126-129).

Nas sociedades modernas, o papel do Estado foi redefinido pela formação de blocos econômicos e políticos, pela perda da soberania e pelo enfraquecimento do poder estatal diante da globalização. Entretanto, o Estado ainda é protagonista e possui um escopo fundamental nas prestações positivas e na proteção contra o abuso de particulares (BARROSO, 2005, p. ix-x).

Devido à mudança de contexto provocada pela constitucionalização da Administração Pública, o direito administrativo necessitou rever alguns conceitos e incorporá-los em sua atuação prática. O surgimento de novos princípios constitucionais que enfatizaram valores democráticos, morais e, sobretudo, conceitos relacionados à dignidade da pessoa humana, obrigou o poder público a se preocupar com o lado existencial, individual e coletivo dos cidadãos, e não somente com questões organizatórias do Estado (BAPTISTA, 2003, p. 89).

A Magna Carta dispõe, em seu artigo 37, sobre a organização da Administração Pública, destacando como princípios basilares para atuação do poder público a legalidade, a impessoalidade, a moralidade, a publicidade e a eficiência. ${ }^{10}$ Tais princípios gerais destinam-se a duas funções. De um lado, à orientação da atuação do governante na prática da função pública administrativa e, de outro, à garantia da qualidade da ação do administrador, que engloba a atividade lícita sobre os negócios públicos e seus recursos, visando o bem-comum da sociedade (SILVA, 2012b, p. 340).

Verifica-se a preponderância de dois polos na atuação governamental, um público e outro privado. Tanto o interesse estatal quanto o interesse particular devem ser satisfeitos, tendo

indivíduos da sociedade. Nos dias de hoje, prefere-se o termo "cidadão" ao buscar o equilíbrio nas relações entre indivíduos, sociedade e Administração Pública.

${ }^{10} \mathrm{O}$ caput do artigo 37 da CF/88 faz menção ao conhecido conjunto de princípios denominado LIMPE, como se vê: “Art. 37. A administração pública direta e indireta de qualquer dos Poderes da União, dos Estados, do Distrito Federal e dos Municípios obedecerá aos princípios de legalidade, impessoalidade, moralidade, publicidade e eficiência [...]". (BRASIL. 1988). 
em vista o dever de garantir a efetivação e a harmonização nas relações sociais dos valores constitucionalmente previstos na Carta Cidadã.

Barroso divide o gênero "interesse público" em duas espécies. A primeira é denominada “interesse público primário" e refere-se à própria razão de ser do Estado, abarcando os conceitos de justiça, segurança e bem-estar social (2005, p. xiii-xvii). Em relação à segunda nomenclatura, o constitucionalista deu o nome de "interesse público secundário". Ela está vinculada ao interesse da própria pessoa jurídica de direito público e à relação jurídica pautada no caso concreto. Ou seja, essa definição trata-se do próprio interesse da Administração Pública que, de forma sucinta, busca a maximização de arrecadação com o mínimo de despesas possível (BARROSO, 2005, p. xiii-xvii).

Ocorre que, em algumas situações, as lides que envolvem o poder público simulam a existência de um interesse público quando, na verdade, trata-se do interesse privado da própria Administração Pública. Isto é, baseia-se em questões como ordem pública, bem da coletividade e outros argumentos congêneres, a fim de buscar a hegemonia do interesse estatal sobre qualquer outro valor envolvido.

Com isso, percebe-se a existência de demandas de interesses particulares do Estado disfarçadas de interesse público no caso concreto. A jurisprudência aponta alguns exemplos em que a atuação da Administração Pública sustenta-se na aplicação do princípio da supremacia do poder público sobre o particular quando, na verdade, não se poderia invocá-lo. É o que se vê abaixo:

RAZÕES DE ESTADO E INTEGRIDADE DA ORDEM CONSTITUCIONAL. Razões de Estado - que muitas vezes configuram fundamentos políticos destinados a justificar, pragmaticamente, ex parte principis, a inaceitável adoção de medidas que frustram a plena eficácia da ordem constitucional, comprometendo-a em sua integridade e desrespeitando-a em sua autoridade - não se legitimam como argumento idôneo de sustentação da pretensão jurídica do Poder Público. Precedentes (STF - RE 256911 / SP, Relator: Min. Celso de Mello. Data de julgamento: 26/09/2000. Segunda Turma. Data de Publicação: DJ 15-12-2000). (BRASIL, 2000) (grifos nossos).

EMENTA: I. Suspensão de segurança: compatibilidade com a Constituição. Verdadeiramente inconciliável com o Estado de Direito e a garantia constitucional da jurisdição seria o impedir a concessão ou permitir a cassação da segurança concedida, com base em motivos de conveniência política ou administrativa, ou seja, a superposição ao direito do cidadão das "razões de Estado"; não é o que sucede na suspensão de segurança, que susta apenas a execução provisória da decisão recorrível: assim como a liminar ou a execução provisória de decisão concessiva de mandado de segurança, quando recorrível, são modalidades criadas por lei de tutela cautelar do direito provável - mas ainda não definitivamente acertado - do impetrante, a suspensão dos seus efeitos, nas hipóteses excepcionais igualmente previstas em lei, é medida de contracautela com vistas a salvaguardar, contra o risco de grave lesão a interesses públicos privilegiados, o efeito útil do êxito provável do recurso da entidade estatal. II. Suspensão de segurança; delibação cabível e necessária do 
mérito do processo principal: precedente (AgSS 846, Pertence, DF 8.11.96). Sendo medida de natureza cautelar, não há regra nem princípio segundo os quais a suspensão da segurança devesse dispensar o pressuposto do fumus boni juris que, no particular, se substantiva na probabilidade de que, mediante o futuro provimento do recurso, venha a prevalecer a resistência oposta pela entidade estatal à pretensão do impetrante. III. Previdência social do Estado: contribuição do segurado: alíquota progressiva conforme a remuneração: argüição de inconstitucionalidade, que em ação direta, o STF reputou inconsistente: grave risco à viabilidade do sistema previdenciário local: suspensão de liminar deferida (STF - SS 1149 AgR / PE, Relator: Min. SEPÚLVEDA PERTENCE. Data de julgamento: 03/04/1997. Tribunal Pleno. Data de Publicação: DJ 09-05-1997). (BRASIL, 1997) (grifos nossos).

Demonstra-se, dessa forma, uma tendência jurisprudencial do direito administrativo que reflete uma hermenêutica de valorização do papel dos princípios constitucionais na interpretação jurídica (SILVA, 2013, p. 128-129). Além de respeitar uma Constituição Cidadã que fora erguida com base nos direitos fundamentais da pessoa humana, o entendimento dos tribunais tem dado primazia à justiça e ao reconhecimento de seus cidadãos (SILVA, 2013, p. 128-129).

Entretanto, torna-se necessária a criação de critérios claros e determinantes para que os argumentos jurídicos consubstanciados em uma frágil alegação da existência de interesse público sejam identificados e corrigidos prontamente. Tais medidas devem se embasar no núcleo central do dispositivo constitucional vigente: os direitos fundamentais da pessoa humana.

Alexandre Santos de Aragão aponta que os argumentos jurídicos atrelados à lei concreta e específica (chamados de "argumentos institucionais") necessitam prevalecer sobre aqueles argumentos subjetivos e abstratos (denominados “argumentos não-institucionais”) (2005, p. 1011). Afirma, ainda, que a prioridade deverá ser concedida aos argumentos objetivos ligados ao texto normativo, em detrimento daquelas afirmações genéricas e metajurídicas relacionadas às crenças individuais de cada julgador e ao seu modo de vivenciar as situações (ARAGÃO, 2005, p. 10-11).

Com isso, legitima-se o texto da regra, constitucional ou legal. Somente no caso de ausência ou lacuna normativa caberia espaço para outras formas de solução para análise dos direitos divergentes.

Para que haja uma real aplicação do conteúdo normativo deve existir uma coerência constante em todo sistema jurídico. É o que se extrai do princípio da unidade da Constituição. Entretanto, a partir dessa constatação surge uma dúvida: poderia haver tamanha compatibilidade sem a prevalência de qualquer critério hierárquico entre as leis?

Alexandre Santos de Aragão afirma que a ausência de uma hierarquia entre os argumentos jurídicos daria margem para decisões subjetivas e arbitrárias, o que permitiria a 
invocação do princípio da supremacia do interesse público sobre o particular em quaisquer hipóteses (ARAGÃO, 2005, p. 18-21). O equilíbrio interno no sistema normativo vigente é fator essencial para a aplicação concreta de todo arcabouço legislativo de forma harmônica e justa.

Aragão destaca que a fragilidade dos argumentos não-institucionais, tais como a necessidade de redução do consumo, de políticas públicas governamentais, da moral pública, dentre outros. Ressalta, ainda, a importância dos argumentos institucionais para garantia de uma sociedade mais justa e democrática (ARAGÃO, 2005, p. 22). Nesse viés, vislumbra-se a importância do respeito e da concretude dos direitos fundamentais da pessoa humana para o desenvolvimento societário equilibrado.

Daniel Sarmento destaca quanto à necessidade de revisão, no âmbito administrativo, do próprio poder de polícia, uma vez que a compreensão sobre os direitos fundamentais consolidou-se nas sociedades modernas e democráticas. A definição clássica do poder de polícia tal como toda atividade da Administração Pública onde há submissão dos direitos individuais aos interesses da coletividade (SARMENTO, 2005, p. 90), restou-se ultrapassada, indo de encontro ao próprio conceito de Estado Democrático de Direito

\section{A BUSCA PELO EQUILÍBRIO NO CASO CONCRETO}

Duas correntes opostas acerca do princípio da supremacia do interesse público sobre o particular destacam-se. A primeira delas, denominada "clássica", defende a existência do aludido princípio. A segunda corrente, por seu turno, chamada de "vanguardista", resguarda a desconstrução do princípio em questão. ${ }^{11}$

Celso Antônio Bandeira de Mello alega que "o princípio da supremacia do interesse público sobre o interesse privado é princípio geral de Direito inerente a qualquer sociedade. É a própria condição de sua existência". Afirma que tal princípio é um pressuposto lógico do convívio social. ${ }^{12}$ Um Estado Democrático deve defender os interesses de todos os grupos

\footnotetext{
${ }^{11}$ A autora tece considerações sobre os defensores de cada uma das correntes. A corrente "clássica" é defendida por Celso Antônio Bandeira de Mello, Maria Sylvia Zanella di Pietro, José dos Santos Carvalho Filho, Romeu Felipe Barccelar Filho, Daniel Wunder Hachem, dentre outros. Já a corrente "vanguardista" é utilizada por Humberto Bergmann Ávila, Daniel Sarmento, Gustavo Binenbojm, Paulo Ricardo Schier, Alexandre Santos Aragão, Patrícia Baptista, Diogo de Figueiredo Moreira Neto e Marçal Justen Filho (SILVA, 2013, p. 130).

$12 \mathrm{O}$ autor destaca que "para prevenir intelecção equivocada ou desabrida sobre o alcance do princípio da supremacia do interesse público sobre o interesse privado na esfera administrativa" é preciso tecer algumas considerações: "as prerrogativas que nesta via exprimem tal supremacia não são manejáveis ao sabor da Administração, porquanto esta jamais dispõe de 'poderes', sic et simpliciter. Na verdade,o que nela se encontram são 'deveres-poderes"”. (MELLO, 2016, p. 99-102).
} 
sociais, de instituições, bem como da própria Administração Pública, estabelecendo um equilíbrio nas relações. Com isso, para que o poder público tenha condições de gerir a sociedade, algumas prerrogativas são, notoriamente, necessárias.

Di Pietro acrescenta:

\begin{abstract}
“As normas de direito público, embora protejam reflexamente o interesse individual, têm o objetivo primordial de atender ao interesse público, ao bem-estar coletivo. Além disso, pode-se dizer que o direito público somente começou a se desenvolver quando, depois de superados o primado do Direito Civil (que durou muitos séculos) e o individualismo que tomou conta dos vários setores da ciência, inclusive a do Direito, substituiu-se a ideia do homem como fim único do direito (própria do individualismo) pelo princípio que hoje serve de fundamento para todo o direito público e que vincula a Administração em todas as suas decisões: o de que os interesses públicos têm supremacia sobre os individuais"(DI PIETRO, 2015, p. 99) (grifo da autora).
\end{abstract}

É incontestável que interesses públicos e privados são indissociáveis e necessários, conjuntamente, para realização dos direitos constitucionalmente previstos. Nas sociedades modernas, os direitos fundamentais são visualizados além da clássica perspectiva individual por meio da chamada "dimensão objetiva dos direitos fundamentais". Assim, tais direitos conferem aos particulares não somente seus direitos subjetivos, como também constituem as “bases jurídicas da ordem jurídica da coletividade” (SARMENTO, 2005, p. 82).

Consuma-se o fato de que os direitos fundamentais são essenciais para toda coletividade e devem ser tutelados pelo poder público, compondo, dessa forma, uma espécie de interesse público da coletividade. Para tanto, verificar-se-ão os possíveis caminhos a serem percorridos com o objetivo de afastar o perigo da existência de um patamar hierárquico privilegiado em torno do princípio da supremacia do interesse público sobre o interesse privado.

Nesse contexto, o princípio da proporcionalidade é tido como um parâmetro para análise de compatibilidade das restrições aos direitos fundamentais constitucionalmente consagrados. Ele costuma ser subdivido em três aspectos, quais sejam, adequação (aptidão do meio para o fim almejado), necessidade (menor restrição possível do direito em questão) e proporcionalidade em sentido estrito (avaliação custo-benefício).

A proporcionalidade em sentido estrito seria, nas palavras de Luís Virgílio Afonso da Silva, um "sopesamento entre a intensidade da restrição ao direito fundamental atingido e a importância da realização do direito fundamental que com ele colide e que fundamenta a adoção da medida restritiva". ${ }^{13}$

\footnotetext{
${ }^{13}$ Luís Virgílio Afonso da Silva traz um exemplo referente ao combate da disseminação da AIDS, no qual o Estado obrigaria que todos os infectados realizassem o exame para sua identificação e que fossem encarcerados todos os HIV positivos. Tal medida seria adequada e necessária, mas não haveria proporcionalidade em sentido estrito,
} 
Explanando sobre o tema, Daniel Sarmento assegura que o emprego da proporcionalidade otimiza a proteção dos bens jurídicos tutelados e evita a restrição demasiada de um princípio em face de outro (SARMENTO, 2005, p. 98-101). Entretanto, afirma que no caso concreto há privilégios apenas para o lado público, o que torna incompatível com a hermenêutica constitucional da concordância prática que busca a harmonização dos bens jurídicos questionados (SARMENTO, 2005, p. 98-101).

Em relação ao princípio da separação dos poderes, o mesmo também poderia ser utilizado para dirimir os conflitos envolvendo a supremacia do interesse público. $\mathrm{O}$ artigo $2^{\circ} \mathrm{da}$ CRFB/88 prevê que os Poderes Legislativo, Executivo e Judiciário são independentes e harmônicos entre si (BRASIL, 1988). Nesse sentido, José Afonso da Silva esclarece que tal princípio trata-se de uma divisão de poderes que "consiste em confiar cada uma das funções governamentais (legislativa, executiva e judiciária) a órgãos diferentes, que tomam os nomes das respectivas funções", e que se fundamentam em dois elementos: especialização funcional e independência orgânica (SILVA, 2012a, p. 114).

No mesmo contexto, o jurista brasileiro faz menção à necessidade da harmonia entre os poderes e a coexistência simétrica entre os mesmos. Mas afirma que não há princípio absoluto e que são necessárias a prática de interferências que busquem o equilíbrio para a efetivação do bem da coletividade, sendo indispensável para evitar o "arbítrio e o desmando de um em detrimento do outro, e especialmente dos governados" (SILVA, 2012a, p. 114).

Binenbojm reflete acerca do surgimento histórico do princípio da separação dos poderes. $\mathrm{O}$ autor descreve o falso relato sobre o surgimento do direito administrativo e do aludido princípio, pautado por um "erro histórico" (BINENBOJM, 2005, p. 119-122). Trata-se, nada mais, que uma "reprodução acrítica de um discurso de embotamento da realidade repetido por sucessivas gerações, constituindo aquilo que Paulo Otero denominou ilusão garantística da gênese" (BINENBOJM, 2005, p. 119-122).

Nesse sentido, o princípio da separação dos poderes seria, na verdade, uma forma de reprodução para garantir as práticas autoritárias do Antigo Regime, não passando de um pretexto para aumentar a esfera de liberdade de decisão da Administração Pública, tornando-se imune ao controle judicial (BINENBOJM, 2005, p. 119-122). Assim, como o princípio da supremacia do interesse público, a origem da separação dos poderes pautava-se na garantia da atuação do poder público e estabelecia uma ordem vertical de interesses, na qual os direitos fundamentais da sociedade permaneciam em último lugar. 
Outra metodologia encontrada para solução dos conflitos refere-se ao uso da técnica da ponderação, descrita por Luís Roberto Barroso e Ana Paula de Barcellos, em linhas claras e explicativas:

\begin{abstract}
"Será preciso um raciocínio de estrutura diversa, mais complexo, que seja capaz de trabalhar multidirecionalmente, produzindo a regra concreta que vai reger a hipótese a partir de uma síntese dos distintos elementos normativos incidentes sobre aquele conjunto de fatos. De alguma forma, cada um desses elementos deverá ser considerado na medida de sua importância e pertinência para o caso concreto, de modo que na solução final, tal qual em um quadro bem pintado, as diferentes cores possam ser percebidas, ainda que uma ou algumas delas venham a se destacar sobre as demais. Esse é, de maneira geral, o objetivo daquilo que se convencionou denominar de técnica da ponderação" (BARCELLOS; BARROSO, 2006, p. 345). (grifo dos autores)
\end{abstract}

Robert Alexy formulou as regras de ponderação, construídas a partir da jurisprudência alemã, descrevendo que a satisfação de um princípio, ou a insatisfação, depende do grau de importância do outro princípio em colisão (ALEXY, 2012, p. 91-94). ${ }^{14} \mathrm{O}$ peso dos princípios deve ser analisado de maneira relativa, sempre.

Existirá ponderação entre os direitos fundamentais onde houver interação de diferentes valores envolvidos. Alexandre de Moraes assevera que a Constituição deve ser apreciada de forma conjunta com a história, a política e a ideologia da conjuntura apresentada em determinado contexto (MORAES, 2000, p. 23). Com isso, constrói-se a melhor forma de aplicação da norma jurídica, colocando-a em confronto com a realidade sociopolíticoeconômica vigente. A técnica de ponderação, oposta nesse cenário de conflito, será exercida buscando dar a máxima aplicabilidade aos direitos fundamentais, bem como o equilíbrio entre eles.

Deflagrada a existência de conflito no caso prático, haverá utilização da técnica da ponderação para analisar qual a melhor solução em cada circunstância. Não há que se falar em exclusão de direitos e princípios, uma vez que eles não se eliminam, mas convivem entre si. Na prática, os direitos fundamentais não devem ser apenas interpretados, mas sim concretizados (BONAVIDES, 2017, p. 624). Com a técnica da ponderação entre princípios colidentes, a distância existente entre o direito positivado e o mundo real dos fatos estreita-se e o conflito existente torna-se passível de solução.

\footnotetext{
${ }^{14}$ Para Cardoso, o fundamento de intervenção pode ser leve, médio e grave. Sendo grave, ele se justificaria pela própria intervenção leve, uma vez que o peso elevado do direito que fundamenta uma intervenção, também justifica a afetação leve de um direito fundamental que com ele colide no caso concreto (CARDOSO, 2010, p. 185-189).
} 
Outra resposta admissível para a questão do conflito existente entre o princípio da supremacia do interesse público e os interesses particulares é o fomento da participação do indivíduo na Administração Pública. A antiga crença liberal de que o poder público seria um mero executor de leis de atuação passiva tornou-se ultrapassada, tendo em vista a versão contemporânea da sociedade pautada pelo princípio da dignidade da pessoa humana.

A eleição do modelo de democracia representativa foi necessária para tornar viável a prática da democracia participativa nos Estados Modernos. Porém, tal modelo apresenta falhas no caso concreto.

A sociedade pluralista conta com inúmeros centros de poder. Com isso, os partidos políticos tornam-se mediadores entre os indivíduos e seus governantes, na busca pela representação dos interesses de todos setores sociais. Entretanto, a insatisfação da vontade geral a partir da ausência de oitiva das diversas camadas que compõem uma estrutura societária, gera dúvidas quanto à validade do próprio sistema de governo (BAPTISTA, 2003, p. 120-123).

Vislumbra-se a necessidade da reformulação das estruturas de participação democrática no âmbito político, contando também com um novo arcabouço legislativo. A complexidade e o dinamismo social exigem a elaboração de um sistema legislativo e político que atenda aos interesses dos mais diversos grupos populares. A atual forma brasileira de aquisição de governo, caracterizada pela democracia representativa, não condiz mais com as necessidades da população.

Diante da indispensabilidade de amplitude do diálogo entre a Administração Pública e os indivíduos, seria colocado em prática o princípio da dignidade da pessoa humana ao contemplar o ser humano como um ser racional e autônomo. Entretanto, é necessário cautela para afastar o "perigo do excesso de retórica", estabelecendo-se uma delimitação à participação do cidadão na seara administrativa (BAPTISTA, 2003, p. 137-148). A autora aponta que tal restrição deveria efetivar-se no espaço fornecido pela lei, situada no âmbito da discricionariedade administrativa (BAPTISTA, 2003, p. 137-148).

Cabe mencionar, ainda nessa conjuntura, que o texto constitucional brasileiro evidencia a garantia do direito de participação pelos particulares na atuação da Administração em alguns de seus dispositivos (BRASIL, 1988). ${ }^{15}$

\footnotetext{
${ }^{15}$ Art. $5^{\circ}$. Todos são iguais perante a lei, sem distinção de qualquer natureza, garantindo-se aos brasileiros e aos estrangeiros residentes no País a inviolabilidade do direito à vida, à liberdade, à igualdade, à segurança e à propriedade, nos termos seguintes: [...] XXXIV - são a todos assegurados, independentemente do pagamento de taxas: a) o direito de petição aos Poderes Públicos em defesa de direitos ou contra ilegalidade ou abuso de poder;

Art. 10. É assegurada a participação dos trabalhadores e empregadores nos colegiados dos órgãos públicos em que seus interesses profissionais ou previdenciários sejam objeto de discussão e deliberação.
} 
Salienta-se, por fim, sobre a importância do princípio da vedação ao retrocesso. $\mathrm{Na}$ prática, o supracitado princípio possui uma estreita relação com a segurança jurídica, caráter inerente ao Estado de Direito, uma vez que toda sociedade democrática prioriza a paz e a justiça social como um dos seus principais objetivos. Assim, o pode público deve garantir que os direitos adquiridos permaneçam vigentes e sejam protegidos, coadunando com a ideia de da estabilidade nas relações sociais pré-estabelecidas.

Nesse âmbito, os direitos fundamentais exigem, por si só, a proteção em face de medidas de involução para que as mesmas não alcancem posições jurídicas já consolidadas, a fim de resguardar as conquistas sociais efetivadas. Interesses públicos e privados, coletivos e individuais, devem ser respeitados para que haja confiança nos atos, nas condutas e nos procedimentos realizados pelo Estado.

\section{CONSIDERAÇÕES FINAIS}

As sociedades transformaram-se e as diversas mudanças ocorridas demonstraram a necessidade de readequação do direito e das normas constitucionais ao novo cenário concebido. Com isso, demonstrou-se no presente estudo a importância da compreensão acerca dos direitos fundamentais e a necessidade de concretização dos mesmos para a consolidação legítima do Estado Democrático de Direito.

A evolução e desenvolvimento sociais pautados nos direitos fundamentais alcançam um efetivo bem-estar coletivo. Nesse viés, constatou-se que a aplicação do princípio da supremacia do interesse público sobre o interesse particular não seria adequado para solução de conflitos

Art. 37. A administração pública direta e indireta de qualquer dos Poderes da União, dos Estados, do Distrito Federal e dos Municípios obedecerá aos princípios de legalidade, impessoalidade, moralidade, publicidade e eficiência e, também, ao seguinte: [...] § $3^{\circ}$. A lei disciplinará as formas de participação do usuário na administração pública direta e indireta, regulando especialmente: I - as reclamações relativas à prestação dos serviços públicos em geral, asseguradas a manutenção de serviços de atendimento ao usuário e a avaliação periódica, externa e interna, da qualidade dos serviços; II - o acesso dos usuários a registros administrativos e a informações sobre atos de governo, observado o disposto no art. $5^{\circ}$, X e XXXIII; III - a disciplina da representação contra o exercício negligente ou abusivo de cargo, emprego ou função na administração pública. Art. 198. As ações e serviços públicos de saúde integram uma rede regionalizada e hierarquizada e constituem um sistema único, organizado de acordo com as seguintes diretrizes: [...] III - participação da comunidade.

Art. 204. As ações governamentais na área da assistência social serão realizadas com recursos do orçamento da seguridade social, previstos no art. 195, além de outras fontes, e organizadas com base nas seguintes diretrizes: [...] II - participação da população, por meio de organizações representativas, na formulação das políticas e no controle das ações em todos os níveis.

Art. 216. Constituem patrimônio cultural brasileiro os bens de natureza material e imaterial, tomados individualmente ou em conjunto, portadores de referência à identidade, à ação, à memória dos diferentes grupos formadores da sociedade brasileira, nos quais se incluem: [...] $\S 1^{\circ}$. O Poder Público, com a colaboração da comunidade, promoverá e protegerá o patrimônio cultural brasileiro, por meio de inventários, registros, vigilância, tombamento e desapropriação, e de outras formas de acautelamento e preservação. (grifo nosso) 
caso seja aplicado nos moldes da época de seu surgimento durante a Revolução Francesa. Isto é, uma atuação arbitrária da Administração Pública em posição de verticalidade frente ao particular, pautada por prerrogativas que embasaram a concretização da prevalência da soberania estatal. Tal cenário não se coaduna com o atual contexto democrático contemporâneo.

No âmbito do direito administrativo, observou-se que a atuação do poder público temse caracterizado pela falta de transparência e por condutas arbitrárias quando se trata da concretização dos interesses públicos. Vislumbrou-se que tal atuação ameaça a materialização dos direitos fundamentais da pessoa humana contidos na Constituição de 1988.

A busca por uma posição de igualdade entre o poder público e o particular demonstrou a necessidade de readequação do princípio da supremacia do interesse público. O antigo conceito de indivíduo, outrora visto como um mero "administrado" obrigado a cumprir as ordens que lhe eram impostas pela Administração Pública, hierarquicamente superior, foi transformado pelo novo cenário em que o ser humano busca a sua posição de horizontalidade ao lado do poder público, agora visto como "cidadão", e não mais como "súdito".

Nesse contexto, constatou-se que o direito administrativo precisa ser revisto sob o enfoque da necessidade de desconstruir alguns conceitos e parâmetros que já não se enquadram mais na realidade contemporânea. Averiguou-se que interesses públicos e privados não estão em contradição, mas em conexão.

Percebeu-se que a ausência de restrições e privações à dignidade da pessoa humana é indispensável para a consolidação de uma base justa do sistema constitucional de um Estado Democrático de Direito. Assim, é notória a necessidade do equilíbrio na resolução dos conflitos existentes entre os interesses da Administração Pública e os interesses dos particulares.

Possíveis caminhos a serem percorridos foram apontados, a fim de coadunar com os ditames democráticos com o objetivo de afastar o perigo da existência de um patamar hierárquico privilegiado em torno do princípio da supremacia do interesse público sobre o interesse privado. Nesse viés, contatou-se que o Estado já não é mais aquele que garante o interesse público, e sim, um instrumento de garantias dos direitos fundamentais de toda a coletividade.

Dessa forma, o princípio da supremacia do interesse público sobre o particular ainda existe e prepondera na atualidade. Não se deve menosprezar sua importante atuação para a garantia dos direitos inerentes aos cidadãos, bem como dos interesses públicos. Entretanto, o aludido princípio deve ser visualizado a partir de um novo conceito. Espera-se que indivíduos, poder público e sociedade atuem, conjuntamente, em prol da efetivação dos direitos 
constitucionalmente previstos na Magna Carta na busca pela concretização do bem comum de toda coletividade.

\section{Referências}

ALEXY, Robert. Teoria dos direitos fundamentais. Tradução de Virgílio Afonso da Silva. 2. ed. 2. tiragem. São Paulo: Malheiros, 2012.

ARAGÃO, Alexandre Santos de. A "Supremacia do Interesse Público" no Advento do Estado de Direito e na Hermenêutica do Direito Público Contemporâneo. In: SARMENTO, Daniel (Org.). Interesses Públicos versus Interesses Privados: Desconstruindo o Princípio de Supremacia do Interesse Público. Rio de Janeiro: Editora Lumen Juris, 2005.

BAPTISTA, Patrícia. Transformações do Direito Administrativo. Rio de Janeiro e São Paulo: Renovar, 2003.

BARCELLOS, Ana Paula de; BARROSO, Luís Roberto. O começo da história. A nova interpretação constitucional e o papel dos princípios no direito brasileiro. In: BARROSO, Luís Roberto (Org.). A nova interpretação constitucional: ponderação, direitos fundamentais e relações privadas. 2. ed. rev e atual. Rio de Janeiro: Renovar, 2006.

BARROSO, Luís Roberto. Curso de Direito Constitucional Contemporâneo. 8. ed. São Paulo: Saraiva, 2019. [Ebook Saraiva Digital]. Não paginado.

BARROSO, Luís Roberto. Prefácio. In: SARMENTO, Daniel (Org.). Interesses Públicos versus Interesses Privados: Desconstruindo o Princípio de Supremacia do Interesse Público. Rio de Janeiro: Editora Lumen Juris, 2005.

BINENBOJM, Gustavo. Da Supremacia do Interesse Público ao Dever de Proporcionalidade: Um Novo Paradigma para o Direito Administrativo. In: SARMENTO, Daniel (Org.). Interesses Públicos versus Interesses Privados: Desconstruindo o Princípio de Supremacia do Interesse Público. Rio de Janeiro: Editora Lumen Juris, 2005.

BONAVIDES, Paulo. Curso de direito constitucional. 32. ed. São Paulo: Malheiros, 2017.

BONAVIDES, Paulo; BEDÊ, Fayga Silveira; LIMA, Francisco Gérson Marques de. Constituição e democracia: estudos em homenagem ao prof. J. J. Gomes Canotilho. São Paulo: Malheiros, 2006.

BRASIL. Constituição (1988). Constituição da República Federativa do Brasil. Brasília, DF. Disponível em: http://www.planalto.gov.br/ccivil_03/constituicao/constituicao.htm. Acesso em: 10 fev 2020.

BRASIL. Supremo Tribunal Federal. Recurso Extraordinário 256911/SP. Relator: Min. Celso de Mello. Diário de Justiça Eletrônico. Brasília, 15 dez. 2000. Disponível em: http://stf.jus.br/portal/jurisprudencia/listarJurisprudencia.asp?s1=\%28RE+269437+SP+CELS $\mathrm{O}+\mathrm{DE}+\mathrm{MELLO} \% 29 \&$ base=baseAcordaos\&url=http://tinyurl.com/y3s85tqe. Acesso em: 10 fev 2020. 
BRASIL. Supremo Tribunal Federal. Suspensão de Segurança 1149 AgR/PE. Relator: Min. Sepúlveda Pertence. Diário de Justiça Eletrônico. Brasília, 09 mai. 1997. Disponível em: http://www.stf.jus.br/portal/jurisprudencia/listarJurisprudencia.asp?s1=\%28SS+1149+PE+SE PULVEDA\%29\&base=baseAcordaos\&url=http://tinyurl.com/yxpdgrq6. Acesso em: $10 \mathrm{fev}$ 2020.

CARDOSO, Henrique Ribeiro. Controle da Legitimidade da Atividade Normativa das Agências Reguladoras. Rio de Janeiro: Lumen Juris, 2010.

DI PIETRO, Maria Sylvia Zanella. Direito Administrativo. 28. ed. São Paulo: Atlas, 2015.

KNOPFHOLZ, Alexandre. As dimensões do processo: análise à luz dos direitos fundamentais. Revista Juridica, [S.1.], v. 26, n. 10, p. 9-35, jun. 2011. ISSN 2316-753X. Disponível em: <http://revista.unicuritiba.edu.br/index.php/RevJur/article/view/168/143> . Acesso em: 21 abr. 2020. doi:http://dx.doi.org/10.21902/revistajur.2316-753X.v26i10.168.

MELlO, Celso Antônio Bandeira de. Curso de Direito Administrativo. 33. ed. rev. e atual. até a Emenda Constitucional 92, de 12.7.2016. São Paulo: Malheiros, 2016.

MENDES, Gilmar Ferreira. Direitos fundamentais e controle de constitucionalidade: estudos de direito constitucional. 3. ed. rev. e ampl. São Paulo: Saraiva, 2007.

MONTEIRO, Cláudia S.; MEZZAROBA, Orides. Manual de Metodologia da Pesquisa no Direito. 6. ed. São Paulo: Saraiva, 2014. E-book Saraiva Digital. [não paginado].

MORAES, Alexandre de. Direito Humanos Fundamentais: teoria geral. 3. ed. São Paulo: Atlas, 2000.

PESSOA, Flávia Moreira Guimarães. Curso de direito constitucional do trabalho: uma abordagem à luz dos direitos fundamentais. Salvador: JusPodivm, 2009.

SARLET, Ingo Wolfgang. A eficácia dos direitos fundamentais. 8. ed. rev. e atual. Porto Alegre: Livraria do Advogado, 2007a.

SARLET, Ingo Wolfgang. Dignidade da pessoa humana e direitos fundamentais na Constituição Federal de 1988. 5. ed. rev. e atual. Porto Alegre: Livraria do Advogado, 2007b.

SARMENTO, Daniel. Interesses Públicos vs. Interesses Privados na Perspectiva da Teoria e da Filosofia Constitucional. In: SARMENTO, Daniel (Org.). Interesses Públicos versus Interesses Privados: Desconstruindo o Princípio de Supremacia do Interesse Público. Rio de Janeiro: Editora Lumen Juris, 2005.

SILVA, Denise Martins Moura. Limites da supremacia do interesse público quando contrapostos ao interesse do cidadão. 2013. 171 f. Dissertação (Programa de Pós-Graduação em Direito da UFS, Constitucionalização do Direito). São Cristóvão, Universidade Federal de Sergipe, 2013. 
SILVA, José Afonso da. Aplicabilidade das normas constitucionais. 8. ed. São Paulo: Malheiros, 2012a.

SILVA, José Afonso da. Comentário contextual à Constituição. 8. ed. atual. São Paulo: Malheiros, 2012b. 